\title{
Evidence of regression of atherosclerosis in primates and man
}

\author{
Mark L. Armstrong \\ M.D. \\ Atherosclerosis Research Center and the Cardiovascular Division, \\ Department of Internal Medicine, University of Iowa College of Medicine, \\ Iowa City, lowa 52242
}

\begin{abstract}
Summary
Atherosclerotic lesions induced in non-human primates regress after the stimulus is removed. That some human lesions also regress is strongly suggested by several types of evidence. The general course of human atherosclerosis is progressive, and the impact of current regimens on the rate of progression is uncertain.

\section{Introduction}

This paper has two objectives. The first objective is to examine the evidence for the thesis that regression of atherosclerosis (a phenomenon demonstrable in experimental animals) occurs in man. The second objective is to relate the evidence to the more general issue of controlling human atherosclerosis.

The notion that atherosclerosis may regress in man has been a topic of controversy for years. The common experience of cardiologists and cardiovascular pathologists is that the clinical manifestations and the lesions of atherosclerosis worsen with time. The evidence that this is not inevitably true is rather restricted, although it continues to accumulate. Owing to the limited information bearing on the regression of human atherosclerosis, it may be instructive to view the question of regression from a larger set of co-ordinates. This may be done by noting what happens to experimentally induced atherosclerosis in other primates before we examine the question of the regression of human atherosclerosis.
\end{abstract}

Regression of atherosclerosis in non-human primates

It is taken for granted that human atherosclerosis and its behaviour cannot be directly equated with induced atherosclerotic lesions in primate studies. The justification for reviewing primate data in the present context may be stated in the following proposition: just as primate studies of atherosclerosis have been helpful in elucidating and confirming aspects of atherogenesis applicable to man, so favourable modification of experimentally established atherosclerosis in primates other than man may

Supported by U.S. Public Health Service Grant HL-14230 and HL-14388 from the National Heart and Lung Institute. be useful in indicating possibilities of change in the human lesion.

The author and his colleagues have studied the Rhesus monkey in particular. In their first investigation of regression (Fig. 1) forty animals were used in a long-term study (Armstrong, Warner and Connor, 1970). After 17 months of atherogenic, hypercholesterolaemic diet, widespread lesions were induced. Twenty monkeys were then given either low-fat or linoleate-enriched diets for $\mathbf{4 0}$ months. Widespread regression was found. The coronary arteries were selected for detailed study.

By precise micromorphometric measurements at preselected sites (Table 1) an average of almost $60 \%$ lumenal narrowing was found in atherosclerotic monkeys, but the regression monkeys had only about $20 \%$. The difference in results between the two re? gression diets was not significant. Because these are relativized data which do not exclude changes such as

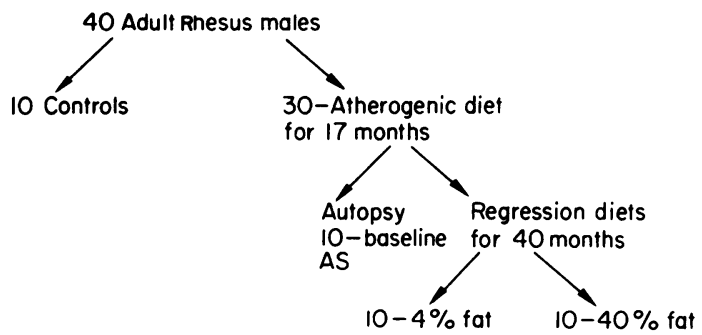

FIG. 1. Design of study.

TABLE 1 . Lumenal narrowing $(\%)$

\begin{tabular}{cccccc}
\hline \multirow{5}{*}{ Main coronary } & & & \\
Group & Left & Right & L.A.D. & L. c'flex & R. dist. \\
\hline AS & $60 \pm 8$ & $56 \pm 7$ & $53 \pm 8$ & $57 \pm 0$ & $65 \pm 10$ \\
R1 & $17 \pm 4$ & $14 \pm 3$ & $21 \pm 4$ & $22 \pm 6$ & $16 \pm 5$ \\
R2 & $25 \pm 5$ & $26 \pm 3$ & $20 \pm 5$ & $23 \pm 6$ & $18 \pm 5$ \\
\hline
\end{tabular}

L.A.D., left anterior descending; L. c'flex, left circumflex; R. dist., distal continuation of right main coronary artery; AS, atherosclerotic, R1, regression monkeys fed low-fat diet; $R 2$, regression monkeys fed linoleate enriched diet. Values are means \pm s.e. 

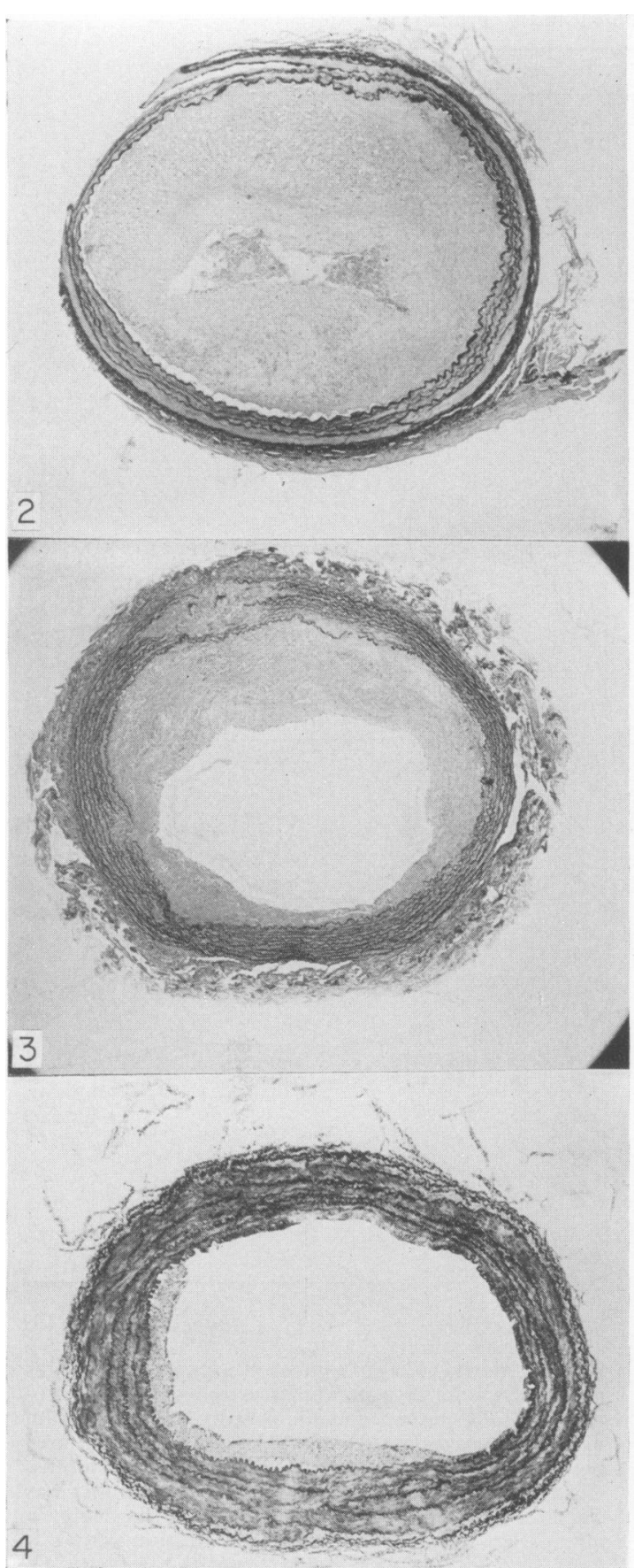

FIGS 2-4. Atherosclerosis and regression are shown in these subclavian arteries.

Fig. 2. A perilumenal layer of thick fibromuscular tissue overlies marked lipid deposition, which is forming small lipid pools in many areas.

[Figure captions continued at foot of next column] arterial dilatation or ectasia they were examined in absolute terms (Table 2).

TABLE 2. Intimal and total transverse areas

\begin{tabular}{lcc}
\hline Group & Intima $\left(\mathrm{mm}^{2}\right)$ & Total artery $\left(\mathrm{mm}^{2}\right)$ \\
\hline AS & $0.720 \pm 0.102$ & $1.93 \pm 0.350$ \\
R1 & $0.138 \pm 0.026$ & $1.58 \pm 0.379$ \\
R2 & $0.213 \pm 0.029$ & $1.63 \pm 0.155$ \\
Control & $<0.010$ & $1.66 \pm 0.272$ \\
\hline
\end{tabular}

AS, atherosclerotic; R1, regression monkeys fed low-fat diet; R2, regression monkeys fed linoleate enriched diet. Values are means \pm s.e.

The same pattern emerged. The total transverse areas of the arteries were not significantly different, but there was a great difference between the intimal area in atherosclerosis and regression.

The theme of marked change after regression was continued in the histological evaluations (Figs 2-4).

The biochemically determined lipid data were considered from two standpoints. First, how did the induced atherosclerotic lesions compare with human lesions as to concentrations of lipid classes; and second, what changes occurred in regression of experimental lesions?

The comparison with widely cited human data is shown in Table 3 . There is very little difference between the elevations in lipid classes found in the atherosclerotic Rhesus monkey and the values in two of the studies, and a greater difference in the third human study. The lipid changes after experimental regression are shown in Table 4. The principal lipid changes are losses from the artery of excess cholesteryl ester and free cholesterol. Triglycerides appear high in coronary arteries because of adventitial contamination (Abdulla, Adams and Baylis, 1969), and because adventitial fat (chiefly triglycerides) is trapped among medial fibres and perhaps enters the intimal lipid pools as well (Dayton, Hashimoto and Pearce, 1965). Triglycerides found to the extent noted in this study and in the previously cited human studies (Table 3) should be regarded as functionally extrinsic to lesion formation.

To this point the data indicate that experimental coronary atherosclerosis regresses morphologically. Combined histological study and biochemical evaluation show that depletion of lipid from the

Fig. 3. A corresponding regression lesion with enlargement of the lumen, more compact fibrous tissue, and small areas of visible residual lipid. Some destruction of the media with replacement fibrosis.

Fig. 4. A small regression lesion, consisting entirely of connective tissue. The induced atherosclerotic lesion from which this lesion evolved is presumed to have been correspondingly smaller than that shown in Fig. 2. All sections stained with Verhoeff-Van Gieson. 
TABLE 3. Coronary lipid content in two primates

\begin{tabular}{lcccc}
\hline & Rhesus & \multicolumn{3}{c}{ Man } \\
\hline Data from: & Armstrong* & Scott $\dagger$ & Meyer $\ddagger$ & Böttcher \\
Total cholesterol $(\mathrm{mg} / \mathrm{g})$ & 51 & 52 & 49 & 70 \\
Lipid class (\%) & & & & \\
Ester cholesterol & 38 & 37 & 25 & 26 \\
Free cholesterol & 14 & 9 & 14 & 13 \\
Triglycerides & 31 & 29 & 40 & 27 \\
Phospholipids & 37 & 25 & 22 & 34 \\
\hline
\end{tabular}

* Armstrong and Megan (1972).

$\dagger$ Scott et al. (1966).

$\ddagger$ Meyer et al. (1966).

$\S$ Böttcher et al. (1960).

TABle 4. Lipid content ( $\mathrm{mg} / \mathrm{g}$ dry weight) of coronary arteries

\begin{tabular}{lccr}
\hline & Control (10) & $\begin{array}{c}\text { Athero- } \\
\text { sclerotic (10) }\end{array}$ & \multicolumn{1}{c}{$\begin{array}{c}\text { Regression } \\
(20)\end{array}$} \\
\hline Total & $6 \cdot 8 \pm 0 \cdot 3$ & $51 \cdot 2 \pm 9 \cdot 3$ & $18 \cdot 1 \pm 1 \cdot 9$ \\
Ester $^{*}$ & $1 \cdot 8 \pm 0 \cdot 2$ & $37 \cdot 6 \pm 8 \cdot 4$ & $11 \cdot 8 \pm 1 \cdot 3$ \\
Free & $5 \cdot 1 \pm 0 \cdot 8$ & $13 \cdot 6 \pm 2 \cdot 3$ & $6 \cdot 3 \pm 0 \cdot 7$ \\
Triglycerides & $15 \cdot 8 \pm 3 \cdot 3$ & $30 \cdot 6 \pm 3 \cdot 9$ & $24 \cdot 1 \pm 2 \cdot 0$ \\
Phospholipids & $27 \cdot 1 \pm 2 \cdot 7$ & $36 \cdot 6 \pm 3 \cdot 9$ & $34 \cdot 2 \pm 3 \cdot 1$ \\
\hline
\end{tabular}

All values are means \pm s.e.; number of monkeys in each group is given in parentheses.

* Cholesteryl moiety.

artery is a major component in regression. What is the fate of arterial connective tissue?

Initial studies on this point have been carried out in Cynomolgus monkeys, a species that appears to develop more fibrotic lesions than do Rhesus monkeys (Armstrong and Megan, 1974). The fibrous protein analyses have been presented in detail elsewhere (Armstrong and Megan, 1975). Arterial collagen changes in atherosclerosis and regression are summarized in Figure 5. After a significant rise in atherosclerosis, there are non-uniform collagen changes in the early phase of regression (up to 200 days), after which there is a levelling-off by the most conservative interpretation or, according to this study, a significant decline in collagen. The interpretation is this: there are fibrogenic lipid moieties within the artery in atherosclerosis that in regression are either depleted or isolated within fibrous capsules these moieties have evoked. Fibroplasia therefore levels off. In the remodelling of the regressed artery, it is plausible that some of the excess collagen may be lysed. Vesselinovitch et al. (1976) have recently presented data that are also compatible with this concept.

Most, perhaps all, studies dealing with regression in non-human primates up to the present are listed in Table 5 (several others are in progress, but no reports are as yet available). Their major theme is

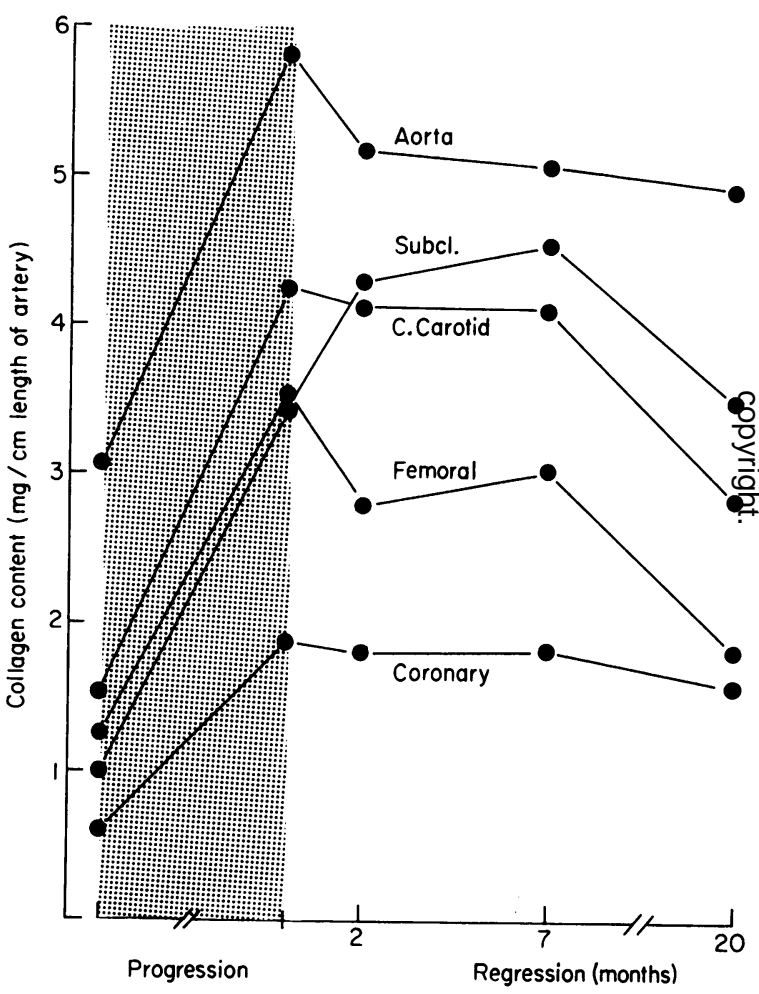

FIG. 5. Arterial collagen content in normal Cynomolgus monkeys, in monkeys after an atherogenic diet, and subsequently after three regression periods. The progression period (atherogenic diet) was 17 months, and the three regression periods were 60 days, 200 days, and 20 months. Collagen content after late regression ( 20 months) was significantly lower than collagen content for reference atherosclerosis at the end of the progression period.

that lesions varying from fatty streaks to severe fatty plaques regress, chiefly because of lipid depletion, and that the connective tissue changes require more delineation before definitive pronouncements can be made. 
TABLE 5. Regression studies in non-human primates

\begin{tabular}{llll}
\hline Year & \multicolumn{1}{c}{ Investigators } & \multicolumn{1}{c}{ Species } & \multicolumn{1}{c}{ Findings } \\
\hline 1968 & Maruffo and Portman & Squirrel & Visible lipid depletion \\
1970 & Armstrong et al. & Rhesus & Regression \\
1971 & Tucker et al. & Rhesus & Regression \\
1972 & De Palma et al. & Rhesus & Regression \\
1974 & Armstrong and Megan & Cynomolgus & Fibrous protein changes \\
1976 & Vesselinovitch et al. & Rhesus & Regression \\
1975 & Radhakrishnamurthy et al. & Rhesus & Connective tissue changes \\
\hline
\end{tabular}

A comparison of induced primate atherosclerosis and human atherosclerosis

In the spectrum of changes induced in the arterial wall by feeding cholesterol and fat to primates, the most advanced and severe lesions may be similar or even identical to the lesions found in human atherosclerosis of clinical significance. Furthermore, myocardial infarction due to experimental coronary atherosclerosis induced by diet with or without injury has been observed (Taylor et al., 1962), and gangrene following peripheral atherosclerosis has been reported (Taylor, Manalo-Estrella and Cox, 1963). Sudden death occurs as a complication of induced coronary atherosclerosis in some primates (Kramsch and Hollander, 1968), and ventricular tachycardia requiring cardioversion has sometimes occurred. These selected citations of target organ damage should be regarded as exceptional occurrences in animal studies. As a rule, lesions in primates are less advanced than in man, and rather typically the experimentally-induced lesions bear the special features noted in hyperlipidaemic humans (Watanabe, Tanaka and Yanai, 1968; Roberts, Levy and Fredrickson, 1970; Armstrong and Warner, 1971).

The question may be raised whether the regression of induced atherosclerosis is due to improvement of less severe lesions with persistence of severe lesions. In the primate the answer is clear: all grades of induced lesions studied to date improve (Armstrong et al., 1970; Tucker et al., 1971). Coronary arteriography has shown significant narrowing in atherosclerotic monkeys; after comparable atherogenic challenge followed by a regression diet of 20 months (Armstrong and Megan, 1974) the coronary arteries did not show occlusive changes (Lauer and Armstrong, unpublished studies). Indeed, it may be said quite categorically that continued growth of induced lesions do not occur in animals when the regimen is changed from an atherogenic hypercholesterolaemic diet to a regression regimen that permits serum lipids to return to normal. Regardless of the degree to which the induced and partially regressible intimal lesion embodies features of the human lesion, however, it is an imperfect replica of human atherosclerosis.

The human atherosclerotic lesion develops during decades of life unlike the experimental lesions that are induced during a period of months, or in the most prolonged experimental investigations during a few years. The factors underlying the occurrence of atherosclerosis in man are often multiple rather than single, unlike the typical study of experimental atherosclerosis induced by marked hypercholesterolaemia. The fibrous proteins of the intimal connective tissue in man may be presumed to be older, more cross-linked, and less vulnerable to remodelling effects. The lipid in clinically significant arterial lesions is principally extracellular except in some instances of human hyperlipidaemias (Armstrong and Warner, 1971). Even if a significant portion of this lipid were depleted, the question of whether the rigid obstructing fibrous skeleton of old lesions would be subsequently remoulded to smaller intralumenal dimensions seems imponderable.

Yet the primate lesion shows amazing metabolic responsiveness: some extracellular as well as intracellular lipid is depleted, there is resolution of necrotic lesions, crystalline lipid tends to diminish slowly, and fibroplasia is eventually contained. To what extent do analogous changes occur in man?

\section{Evidence for regression of atherosclerosis in man}

Data bearing on regression of human atherosclerosis are summarized in Table 6. The investigations tabulated are representative of the types of evidence that have been adduced for and against regression of atherosclerosis in man. Not all investigators who found a favourable change regarded it as regression. Eilerson and Faber (1960), for example, are sometimes cited as having found regression, but they interpreted their data as showing arrest of atherosclerosis in comparison with progression in controls. Before 1960, the undesirable settings of war, infection, and cancer or other wasting disease provided the chief sources of evidence that the rate of progression of atherosclerosis could be altered.

During the current period the use of hypolipidaemic agents, and sometimes surgery, has been evaluated together with diet changes and exercise, and has yielded a measure of further evidence that regression sometimes occurs. Ileal by-pass has been followed by changes in coronary arteriograms interpreted as regression in a few patients (Knight et al., 1972). The famous case of Starzl who under- 
TABLE 6. Regression studies in human atherosclerosis

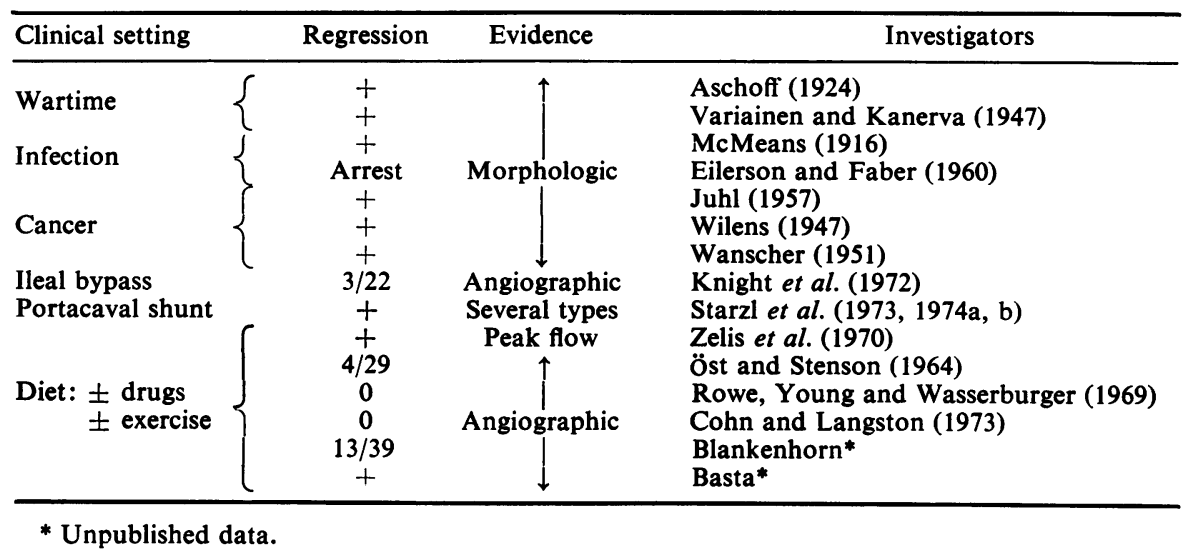

went portacaval shunt for homozygous Type II hyperlipoproteinaemia showed regression of atherosclerotic lesions but died suddenly from her advanced myocardial disease (Starzl et al., 1973, 1974a, b). Among non-surgical regimens both negative and positive results are shown. The negative studies listed are of coronary disease. In retrospect, we might fault them for suboptimal risk factor reduction and perhaps too short an interval between angiographic studies but, without question, there is no evidence of regression and there is some for progression.

Blankenhorn has studied the femoral arteries of patients who have survived a myocardial infarct by precise angiographic techniques. After a programme of weight loss, prudent diet, and exercise, he has found evidence of regression in one-third of his patients. Basta has evaluated a single patient instructively. He found angina, hyperlipidaemia, and bilateral renovascular hypertension with high renin levels. After prolonged treatment with diet and combined drug therapy, this 49-year-old woman had remarkable clinical improvement, and a ten-fold reduction in plasma renin to normal; follow-up angiographic studies showed apparent regression of lesions in the coronary arteries and unequivocal regression in the renal arteries.

\section{The control of atherosclerosis in man}

The phenomenon of regression in primates has been observed to date only with reference to lesions induced with profound hypercholesterolaemia. The most common background found in human lesions that have shown evidence of regression during clinical studies is likewise hyperlipidaemia. The interplay of multiple risk factors so frequently found in human atherosclerosis has not been evaluated in experimental regression. There is no doubt that hypertension, components of tobacco smoke, and diabetes accelerate intimal connective tissue changes 8 and cause a more advanced lesion.

Can such lesions regress? Recent studies of $\overparen{ }$ cholesterol kinetics in severe human lesions have응 shown a turnover time of one to two years in patients with a variety of risk factors (Jagannathan, 1974). $\complement$ This information is of great interest because it suggests that lipid depletion may be possible. Until $\overrightarrow{0}$ actual depletion of human arterial lipid has bee shown in significant lesions, however, this line evidence for regression is speculative.

The totality of the data in man, which must include our daily experience, is that there is fairly acceptable evidence of regression of atherosclerosis, $\frac{\Phi}{8}$ but that progression seems overwhelmingly to be the rule. It is entirely possible that most current regimens, $\frac{}{3}$ as prescribed by us and carried out by patients, are insufficient to alter this pattern. Can this pattern be altered? In a sense, this is to ask whether it is possible to accomplish generally and by more $\frac{0}{3}$ acceptable means what has been reported to occur as a result of wartime privations, cancer, and wasting 3 . disease.

The issue is in doubt, but one comment is relevant. It is not helpful to group the special problems of 0 myocardial disease caused by atherosclerosis with those of the disease in the vessel wall, and call the sum of the two the coronary problem. Myocardial disease carries its own risks, separate from those $\mathcal{N}$ posed by the status of the nutrient arteries. Only N primary prevention studies may separate the two.

\section{Acknowledgments}

I wish to thank the following colleagues for providing access to unpublished data and permitting me to include? portions relevant to this presentation: Dr Lotfy Basta, $\square$ Oklahoma City; Dr David H. Blankenhorn, Los Angeles; $\bar{O}$ and Drs Draga Vesselinovitch and Robert W. Wissler, Chicago. 


\section{References}

Abdulla, Y.H., Adams, C.W.M. \& Baylis, O.B. (1969) Relative absence of triglycerides in coronary atherosclerotic disease. Journal of Atherosclerosis Research, 10, 149.

Armstrong, M.L. \& Megan, M.B. (1972) Lipid depletion in atheromatous coronary arteries in Rhesus monkeys after regression diets. Circulation Research, 30, 675.

Armstrong, M.L. \& Megan, M.B. (1974) Responses of two macaque species to atherogenic diet and its withdrawal. In: Atherosclerosis, Proceedings of Third International Symposium on Atherosclerosis (Ed. by G. Schaffer and A. Weizer. West Berlin, Springer-Verlag, New York.

Armstrong, M.L. \& Megan, M.B. (1975) Arterial fibrous proteins in Cynomolgus monkeys after atherogenic and regression diets. Circulation Research, 36, 256.

ARMSTRONG, M.L. \& WARNER, E.D. (1971) Morphology and distribution of diet-induced atherosclerosis in Rhesus monkeys. Archives of Pathology, 92, 395.

Armstrong, M.L., WARnER, E.D. \& ConNor, W.E. (1970) Regression of coronary atheromatosis in Rhesus monkeys. Circulation Research, 25, 59-67.

Aschoff, L. (1924) Lectures in Pathology Chapter 6, Atherosclerosis, p. 131, Lane Lecture, San Francisco, Hoeber, New York.

BötTCher, C.J.F., Boelsma-van Houte, E., TER HaAR ROMENY-WACHTER, C.C., WOODFORD, F.P. \& VAN GENT, C.M. (1960) Lipid and fatty-acid composition of coronary and cerebral arteries at different stages of atherosclerosis. Lancet, ii, 1162.

Cohn, K. \& Langston, M. (1973) Effect of clofibrate on progression of coronary disease: A prospective, angiographic study in man. Circulation 47-48 (Suppl. 4), 155.

Dayton, S., Hashimoto, S. \& Pearce, M.L. (1965) Influence of a diet high in unsaturated fat upon composition of arterial tissue and atheroma in man. Circulation, 32, 911.

De Palma, R.G., Insul, W., JR, Bellon, E.M., Roth, W.T. \& Robinson, A.V. (1972) Animal models for the study of progression and regression of atherosclerosis. Surgery, 72, 268.

EILERSON, P. \& FABER, M. (1960) The human aorta. Archives of Pathology, 70, 103.

Jagannathan, S.N., Connor, W.E., Baker, W.H. \& BHATTACHARYYA, A. (1974) The turnover of cholesterol in human atherosclerotic arteries. Journal of Clinical Investigation, 54, 366.

JuHL, S. (1957) Cancer and atherosclerosis. II. Applicability of postmortem statistics in the study of negative correlation. Acta pathologica microbiologica scandinavica, 41, 99.

Knight, L., Scheibel, R., Amplatz, K., Varco, R.L. \& BuCHWALD, H. (1972) Radiographic appraisal of the Minnesota partial ileal bypass study. Surgical Forum, 23, 141.

KramsCh, D.M. \& Hollander, W. (1968) Occlusive atherosclerotic disease of the coronary arteries in monkey (Macaca irus) induced by diet. Experimental Molecular Pathology, 9, 1.

Marufro, C.A. \& Portman, O.W. (1968) Nutritional control of coronary artery atherosclerosis in the squirrel monkey. Journal of Atherosclerosis Research, 8, 237.

McMeans, J.W. (1916) Superficial fatty streaks: an experimental study. Journal of Medical Research, 31, 41.

Meyer, B.J., Meyer, A.C., Pepler, W.J. \& Theron, J.J. (1966) Chemical composition of the aorta, coronary and cerebral arteries of Europeans and Bantu. American Heart Journal, 71. 68.

Öst, C.R. \& Stenson, S. (1964) Regression of atherosclerosis during nicotinic acid therapy: a study in man by means of repeated arteriographies. In: Niacin in Vascular Disorders and Hyperlipemia (Ed. by R. Atschul), pp. 243-262. Charles C. Thomas, Springfield.

RadHAKRISHNAMURThy, B., Eggen, D.A., KoKatnur, M., Jirge, S., Strong, J.P. \& Berenson, G.S. (1975) Composition of connective tissue in aortas from Rhesus monkeys during regression of diet-induced fatty streaks. Laboratory Investigation, 33, 136.

Roberts, W.C., Levy, R.I. \& Fredrickson, D.S. (1970) Hyperlipoproteinemia. Archives of Pathology, 90, 46.

ROWE, G.G., Young, W.P. \& WASSERBURGER, R.H. (1969) The effects of reduced serum cholesterol on human coronary atherosclerosis. Circulation, 39 (Suppl. 3), 22.

SCOTT, R.F.. DaOUd, A.S., Workman, B., Morrison, E.S. \& JARMOLYCH, J. (1966) Proliferation and necrosis in coronary and cerebral arteries. Journal of Atherosclerosis Research, 6, 499.

Starzl, T.E., Chase, H.P., Putnam, C.W. \& Nora, J.J. (1974a) Follow-up of patient with portacaval shunt for the treatment of hyperlipidaemia. Lancet, ii, 714.

Starzl, T.E., Chase, H.P., Putnam, C.W., Nora, J.J., Fennell, R.H., JR \& Porter, K.A. (1974b) Portacaval shunt in hyperlipidaemia. Lancet, ii, 1263.

Starzl, T.E., Putnam, C.W., Chase, H.P. \& Porter, K.A. (1973) Portacaval shunt in hyperlipoproteinaemia. Lancet. ii, 940.

Taylor, C.B., Cox, G.E., Manalo-Estrella, P. \& SouthWORTH, J. (1962) Atherosclerosis in rhesus monkeys. II. Arterial lesions associated with hypercholesterolemia induced by dietary fat and cholesterol. Archives of Patho$\log y, 74,16$.

Taylor, C.B., Manalo-Estrella, P. \& Cox, G.E. (1963) Atherosclerosis in Rhesus monkeys. V. Marked dietinduced hypercholesterolemia with xanthomatosis and severe atherosclerosis. Archives of Pathology, 76, 239.

Tucker, C.F., Catsulis, C., Strong, J.P. \& Eggen, D.A. (1971) Regression of early cholesterol-induced aortic lesions in Rhesus monkeys. American Journal of Patho$\log y, 65,493$.

Variainen, I. \& Kanerva, K. (1947) Arteriosclerosis and wartime. Annales medicinae experimentalis et biologiae Fenniae, 36, 748.

Vesselinovitch, D., Wissler, R.W., Hughes, R. \& BorensZTAJN, J. (1976) Reversal of advanced atherosclerosis in Rhesus monkeys. Atherosclerosis, 23, 155.

Wanscher, O., Clemmesen, J. \& Nielsen, A. (1951) Negative correlation between atherosclerosis and carcinoma. British Journal of Cancer, 5, 172.

Watanabe, T., Tanaka, K. \& Yanai, N. (1968) Essential familial hypercholesterolemic xanthomatosis: an autopsy case with special reference to pathogenesis of its cardiovascular lipidosis. Acta pathologica japonica, 18, 319.

WiLENS, S.L. (1947) Resorption of arterial atheromatous deposits in wasting disease. American Journal of Pathology, 23, 793.

Zelis, R., Mason, D.T., Braunwald, E. \& Levy, R.I. (1970) Effects of hyperlipoproteinemia and their treatment on the peripheral circulation. Journal of Clinical Investigation, 49, 1007. 